\title{
Estimation of mass change trends in the Earth's system on the basis of GRACE satellite data, with application to Greenland
}

\author{
C. Siemes - P. Ditmar - R. E. M. Riva - D. C. Slobbe • \\ X. L. Liu - H. Hashemi Farahani
}

Received: 25 March 2011 / Accepted: 19 June 2012 / Published online: 12 July 2012

(C) The Author(s) 2012. This article is published with open access at Springerlink.com

\begin{abstract}
The Gravity Recovery and Climate Experiment (GRACE) satellite mission measures the Earth's gravity field since March 2002. We propose a new filtering procedure for post-processing GRACE-based monthly gravity field solutions provided in the form of spherical harmonic coefficients. The procedure is tuned for the optimal estimation of linear trends and other signal components that show a systematic behavior over long time intervals. The key element of the developed methodology is the statistically optimal Wienertype filter which makes use of the full covariance matrices of noise and signal. The developed methodology is applied to determine the mass balance of the Greenland ice sheet, both per drainage system and integrated, as well as the mass balance of the ice caps on the islands surrounding Greenland. The estimations are performed for three 2-year time intervals (2003-2004, 2005-2006, and 2007-2008), as well as for the 6-year time interval (2003-2008). The study confirms a significant difference in the behavior of the drainage systems over time. The average 6-year rate of mass loss in Greenland is estimated as $165 \pm 15 \mathrm{Gt} /$ year. The rate of mass loss of the ice caps on Ellesmere Island (together with Devon Island), Baffin Island, Iceland, and Svalbard is found to be
\end{abstract}

C. Siemes · P. Ditmar $(\varangle)$ - R. E. M. Riva - D. C. Slobbe

X. L. Liu · H. Hashemi Farahani

Delft University of Technology, PO Box 5048,

2600 GA Delft, The Netherlands

e-mail: p.g.ditmar@tudelft.nl

Present Address:

C. Siemes

European Space Agency, Keplerlaan 1,

2201 AZ Noordwijk, The Netherlands

Present Address:

X. L. Liu

Fugro Intersite B.V., Dillenburgsingel 69,

2263 HW Leidschendam, The Netherlands
$22 \pm 4,21 \pm 6,17 \pm 9$, and $6 \pm 2 \mathrm{Gt} /$ year, respectively. All these estimates are corrected for the effect of glacial isostatic adjustment.

Keywords Satellite gravimetry - Time-variable gravity . Ice sheet - Mass balance

\section{Introduction}

Mass change trends in the Earth's system reflect various processes inside the Earth and at the Earth's surface, including glacial isostatic adjustment (GIA), post-seismic deformation triggered by earthquakes, depletion of ground water stocks, long-term variations of water level in open water bodies, melting of mountain glaciers, and shrinking of ice sheets and caps in polar areas. Monitoring such processes is vital for better understanding properties of the solid Earth, for a more efficient water management, for quantifying and forecasting the processes associated with global climate change, and for many other applications.

One of the modern techniques to monitor mass variations in the Earth's system is satellite gravimetry. Mass transport inside the Earth and at the Earth's surface manifests itself in temporal variations of the gravity field, which can be directly measured from space. On the basis of the collected data, mass variations can be derived in the form of a time series of $2 \mathrm{D}$ maps (Wahr et al. 1998).

Gravimetric signals associated with mass re-distribution are extremely weak, which means that (a) advanced observation techniques are required and (b) only the integrated effect of mass changes in relatively large areas can be measured, so that the spatial resolution of the results is limited. The first and the only satellite gravimetry mission which allows mass variations to be observed down to the spatial 
scale of about $300 \mathrm{~km}$ is the Gravity Recovery and Climate Experiment (GRACE) launched in 2002 (Tapley et al. 2004). On the basis of GRACE K-Band Ranging (KBR) data, a number of alternative time-series of temporal mass variations are being produced at several research institutes (Bettadpur 2007; Schmidt 2007; Ilk et al. 2005; Luthcke et al. 2006b; Lemoine et al. 2007; Liu et al. 2010). The typical temporal resolution of those time series is 1 month. They can be used, among other, for a quantification of mass change trends in different geographical areas.

Temporal gravity field variations recorded by satellite gravimetry reflect the integrated effect of all geophysical processes involved. In order to isolate the process of interest, the contribution of other processes has to be subtracted from the data, for which purpose appropriate background models have to be used. In particular, signals associated with tides of all types, as well as with a non-tidal mass transport in the atmosphere and oceans, are typically removed from the collected satellite gravimetry data at the pre-processing stage.

In order to properly deal with the Earth's gravity field models based on GRACE data, it is important to understand their noise characteristics. Noise in those models reflects instrument errors, the mission geometry, uncertainties in background models, and, possibly, limitations of current data processing strategies. The noise in unconstrained GRACEbased solutions (i.e., solutions not subject to a regularization or filtering) forms a peculiar pattern, which is often referred to as along-track 'stripes'. The primary reason for this pattern is the anisotropic sensitivity of the mission; it senses the north-south component of gravity field gradient much better than the east-west one (Liu et al. 2010).

In order to use GRACE-based estimates for a quantification of mass change processes, one has to ensure that noise in the resulting model is reduced to a minimum. A commonly used way to do so is to apply an appropriate filter. However, filtering does not only suppress noise but also blurs the signal and becomes one of the factors limiting the spatial resolution. Due to the blurring, a part of the signal in a region may "leak" into adjacent regions. Such a signal leakage may cause significant errors when mass variations (including mass change trends) per region are quantified.

In an attempt to minimize blurring of the derived mass change trends, we have developed a dedicated filter. Conceptually, it is somewhat similar to the Wiener-type filter for post-processing monthly gravity field solutions proposed earlier by Klees et al. (2008). Such a filter is based on statistically optimal estimation principles and makes use of the full noise and signal covariance matrices. In our filtering procedure, the signal is defined as a linear combination of six or seven components spanning a sufficiently long time interval: a constant bias, a linear change (trend), annual and semi-annual variations, and (optionally) a quadratic term (acceleration). All these components are jointly estimated from unconstrained monthly GRACE solutions by means of a least-squares adjustment. We obtain the joint noise covariance matrix of all the components by propagating the noise covariance matrices of the unconstrained monthly GRACE solutions. Next, we estimate signal covariance matrices, separately for each of the components. Using the obtained noise and signal covariance matrices, we construct a filter for postprocessing the components under consideration, which is tailored, in particular, for the estimation of GRACE-based mass change trends.

Of course, it is also possible to derive trends and other signal components directly from optimally filtered monthly solutions. However, we find the new procedure more appropriate because the trend estimates are based on several years of GRACE data and, consequently, are less noisy than an individual monthly solution. This means that filtering applied in our case can be less aggressive, so that more signal is preserved. In other words, the spatial resolution of the results obtained by the new procedure can be higher.

To analyze the performance of the developed filter, we exploit unconstrained monthly gravity field solutions based on GRACE data spanning the time interval from February 2003 to December 2008, excluding June 2003. The same solutions were used earlier to produce the first release of the DEOS Mass Transport (DMT-1) model (Liu et al. 2010) at the Delft Institute of Earth Observation and Space Systems (DEOS) of the Delft University of Technology. Furthermore, we use maps of the estimated mass change trends to obtain the mass balance for Greenland and the surrounding islands. Such a choice of the application area is triggered by a high importance of an accurate quantification of long-term changes in the polar ice sheets due to their effect on global sea level rise and the complex linkage to global climate (IPCC 2007).

In general, changes in the ice mass can be either estimated by the mass balance method (van den Broeke et al. 2009; Rignot et al. 2011) or derived from observations. The idea of the mass balance method is to model individual components of the ice sheet mass balance: precipitation, surface ablation, and peripheral ice discharge. The former two are estimated on the basis of meteorological data, whereas the ice discharge is computed by combining information about ice velocities, which are usually derived from satellite radar interferometry observations (Rignot et al. 2006; van den Broeke et al. 2009), and ice thickness data. As any other modeling technique, the mass balance method is heavily dependent on the availability, accuracy, and consistency of input data, as well as on the assumptions adopted to replace missing information (e.g., about the vertical profile of ice velocities). It is also possible to derive the ice mass balance in a more straightforward way, i.e., without building models describing the ice behavior. Apart from satellite gravimetry, a number of remote sensing techniques can be used for that purpose: satellite 
radar altimetry (Zwally et al. 2005), satellite laser altimetry (Zwally et al. 2002, 2011; Slobbe et al. 2008; Sørensen et al. 2011), airborne laser altimetry (Abdalati et al. 2001; Krabill et al. 2004), and stereo satellite imagery (Stearns et al. 2007). All these observation techniques deduce the mass balance of the ice sheets from measurements of elevation changes and lead to a relatively high spatial resolution. However, their temporal and, sometimes, spatial coverage is incomplete. Furthermore, the transformation of the observed volume changes into mass changes requires that the densities of the materials involved are known with a sufficiently high accuracy.

Satellite gravimetry is a viable alternative to all the methodologies mentioned above. It is the only technique that provides a direct measurement of the mass changes. A number of authors have already used GRACE data to estimate the mass balance of the Greenland ice sheet and the surrounding ice caps, either in a stand-alone fashion (Luthcke et al. 2006a; Wouters et al. 2008; Velicogna 2009; Schrama and Wouters 2011; Baur and Sneeuw 2011) or in combination with other techniques (Slobbe et al. 2009; van den Broeke et al. 2009; Gardner et al. 2011). However, an accurate quantification of ice mass changes in that area remains challenging. Firstly, the spatial pattern of mass losses in Greenland shows sharp spatial variations at the scales comparable with or smaller than the spatial resolution of GRACE. Secondly, ice mass changes in the Canadian Arctic Archipelago occur very close to the western coast of Greenland, so that a separation of the two signals remains problematic. By increasing the spatial resolution of trend estimates, one may separate ice mass loss signals in Greenland and in Canadian Arctic Archipelago more reliably. This is one more reason why we have chosen Greenland and the surrounding islands to analyze the performance of the proposed high-resolution filtering procedure.

We produce maps of mass change trends for 2- and 6 -year time intervals, which allow mass variations in space and time to be investigated. Furthermore, we make an attempt to quantify the mass balance both of the entire Greenland ice sheet and of its individual drainage systems. In addition, we estimate the mass balance of the ice caps on the islands surrounding Greenland: (a) Ellesmere Island with Devon Island, (b) Baffin Island, (c) Svalbard, and (d) Iceland. In order to correct the obtained estimates for the signal leakage, we compute and apply appropriate scaling factors.

To assess the errors in the obtained mass balance estimates, we follow an approach similar to the one of Velicogna et al. (2006). We consider the formal error of the obtained trend, uncertainty of the GIA correction and uncertainties related to signal leakage between the considered regions. The variances of all those errors are summed up to produce the variance of the final error in the mass balance estimates.

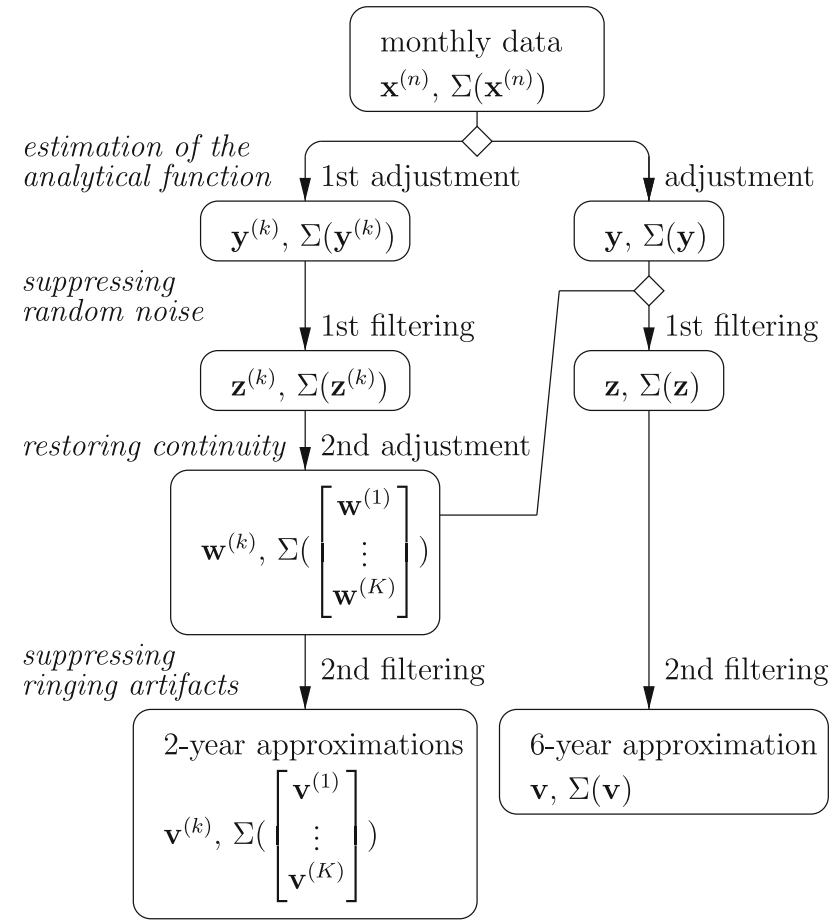

Fig. 1 Processing scheme for estimating trends in GRACE data. The flow-chart uses the same symbols that are used in the detailed description of the developed scheme

\section{Methodology}

\subsection{Overview}

The adopted data processing scheme consists of two branches (Fig. 1). The target of the first branch is to estimate the trend and other mass change parameters per 2-year time interval (2003-2004, 2005-2006, and 2007-2008). The second branch deals with the entire 6-year interval (2003-2008). The computations are performed to spherical harmonic degree 120 .

The first branch starts from fitting an analytical function to the spherical harmonic coefficients of unconstrained monthly GRACE solutions within the time intervals under consideration. Apart from the trend, the analytical function includes also five other components: a constant bias, annual variations, and semi-annual variations. In this way, we try to mimic the most prominent signals in the time series under consideration. In particular, the semi-annual term is needed to achieve a better approximation of the yearly cycle in the polar regions, which is characterized (if present) by a rapid snow mass decline in spring or summer and a slow accumulation of snow mass in the cold season. At the same time, we do not incorporate the sinusoidal term with the 161-day period, which could absorb the signal associated with the $S_{2}$ tide aliasing. It has been shown (Chen et al. 2009) that such a signal is relatively small for the most of the Earth's surface, 
including Greenland, provided that a state-of-the art model of ocean tides, like FES2004 (Lyard et al. 2006), is used in GRACE data processing. The mass change acceleration is not estimated at this point either because a 2 -year time interval is too short to do that reliably. The fit is performed by means of a least-squares adjustment incorporating the full covariance matrices of the monthly solutions.

In the second stage of the processing scheme, we apply a filter to suppress noise inherited by the estimated components from GRACE data.

When the estimated analytical functions for the 2-year time intervals are formally catenated to describe the mass changes over the entire time span, the result is a discontinuous function. Since jumps in the mass change are not consistent with the reality, we restore the continuity in the third stage of the processing scheme by means of a second adjustment.

The final estimated components of the analytical function may exhibit ringing artifacts when represented in the form of spatial maps. In order to suppress these artifacts, we perform a "fine-tuning" of the obtained solutions by applying the second filter in the fourth stage of the processing scheme. In this way, we obtain optimally filtered trend estimates for 2-year time intervals.

The trend for the entire 6-year time interval is estimated in the second branch of the developed procedure. This is done in a similar way as in case of 2-year trends, though some elements of the applied procedure are somewhat different. Following Velicogna (2009), we extend the analytical function with a quadratic term (mass change acceleration), so that a better fit to GRACE data can be achieved. The signal covariance matrix is now based on the estimates already obtained for the 2-year time intervals because one cannot derive it reliably from one signal sample only. In fact, the need for at least three independent samples of each component was one of the main reasons to make estimations not only over the entire 6-year time interval but also over 2-year intervals.

The second least squares-adjustment is not needed in case of the single time interval because no space is left in this case for discontinuities. The ringing artifacts are suppressed in the final stage in the same way as before.

In further sub-sections, the developed methodology is presented in more detail.

\subsection{Formal description of input data}

The input for the developed procedure is a time series of monthly gravity field solutions represented with spherical harmonic coefficients and supplied with the corresponding noise covariance matrices. Let the vector $\mathbf{x}_{i}$ denote the set of spherical harmonic coefficients for month $i$, and $\mathbf{S}\left(\mathbf{x}_{i}\right)$ be the error covariance matrix of $\mathbf{x}_{i}$. The size of them is equal to $M$ and $M \times M$, respectively, where $M$ is the number of spherical harmonic coefficients in a monthly solution. Obviously, the monthly error covariance matrix can be obtained as $\mathbf{S}\left(\mathbf{x}_{i}\right)=\mathbf{N}_{i}^{-1}$, where $\mathbf{N}_{i}$ is the normal matrix used in the leastsquares estimation of $\mathbf{x}_{i}$ (provided that a realistic stochastic model of noise in the data is exploited). We emphasize that the coefficients in $\mathbf{x}_{i}$ are not regularized or filtered and, therefore, are contaminated by severe along-track stripes, which are typical for unconstrained gravity field models based on GRACE data.

\subsection{2-year estimations}

\subsubsection{Unconstrained estimation of the trend and other mass change parameters}

First of all, the spherical harmonic coefficients are used to estimate the analytical function

$$
\begin{aligned}
\mathbf{x}(\tau)= & \mathbf{y}_{1}+\mathbf{y}_{2} \tau+\mathbf{y}_{3} \cos (2 \pi \tau)+\mathbf{y}_{4} \sin (2 \pi \tau) \\
& +\mathbf{y}_{5} \cos (4 \pi \tau)+\mathbf{y}_{6} \sin (4 \pi \tau),
\end{aligned}
$$

which contains, in particular, vector $\mathbf{y}_{2}$ describing the linear trend. The other parameters are defined as follows: $\tau=\frac{t-t_{0}}{T}$ is the normalized time, with time interval $T$ being equal to 1 year and the reference time $t_{0}$ referring to the middle of the time interval under consideration; vector $\mathbf{y}_{1}$ is the bias with respect to a long-term mean gravity field, and $\mathbf{y}_{3}$ to $\mathbf{y}_{6}$ account for annual and semi-annual variations. The length of the vectors $\mathbf{y}_{1}, \ldots \mathbf{y}_{6}$ is equal to $M$. The vector

$\mathbf{y}^{T}=\left[\mathbf{y}_{1}^{\mathrm{T}} \ldots \mathbf{y}_{6}^{\mathrm{T}}\right]$

is estimated by means of a least-squares adjustment under assumption that noise in different monthly solutions is uncorrelated. The exploited observation equations can be written as

$\mathbf{x}_{i}=\left(\mathbf{A}_{i} \otimes \mathbf{I}_{\mathbf{M}}\right) \mathbf{y}$

where $\otimes$ denotes the Kronecker product, $\mathbf{I}_{\mathbf{M}}$ is the identity matrix of the size $M \times M$, and

$\mathbf{A}_{i}=\left[\begin{array}{lll}1 & \left.\tau_{i} \cos \left(2 \pi \tau_{i}\right) \ldots \sin \left(4 \pi \tau_{i}\right)\right]\end{array}\right.$

with $\tau_{i}$ being the normalized time associated with the middle of month $i$. Using these definitions, we can readily write the normal equations to be solved:

$\mathbf{N y}=\mathbf{b}$,

where

$\mathbf{N}=\sum_{i}\left(\mathbf{A}_{i}^{\mathrm{T}} \mathbf{A}_{i}\right) \otimes \mathbf{I}_{\mathbf{M}} \quad$ and $\quad \mathbf{b}=\sum_{i}\left(\mathbf{A}_{i}^{\mathrm{T}} \otimes \mathbf{I}_{\mathbf{M}}\right) \mathbf{x}_{i}$. 


\subsubsection{Wiener filtering}

The estimated parameters $\mathbf{y}$ inherit the errors of the observations $\mathbf{x}_{i}$. Therefore, a proper post-processing of the results is required. To that end, we use a statistically optimal Wienertype filter, inspired by the one designed for monthly gravity field solutions (Klees et al. 2008). The basic idea is to regard the estimated parameters $\mathbf{y}$ as a realization of a stochastic process $\mathcal{Y}$. Let us introduce its signal covariance matrix $\mathbf{S}^{(y)}=$ $E\left(\mathcal{Y} \mathcal{Y}^{\mathrm{T}}\right)$ and its noise covariance matrix $\mathbf{S}^{(n)}=E((\mathcal{Y}-$ $\left.E(\mathcal{Y}))(\mathcal{Y}-E(\mathcal{Y}))^{\mathrm{T}}\right)$, where $E$ is the expectation operator. Then, the optimal filter is defined as

$\mathbf{W}=\mathbf{S}^{(y)}\left(\mathbf{S}^{(n)}+\mathbf{S}^{(y)}\right)^{-1}$

and the filtered parameters $\mathbf{z}$ are obtained as

$\mathbf{z}=\mathbf{W y}$.

More details can be found in Klees et al. (2008) and Liu et al. (2010).

The noise covariance matrix is readily computed as $\mathbf{S}^{(n)}=$ $\mathbf{N}^{-1}$, where $\mathbf{N}$ is the normal equation matrix defined by Eq. (5). The estimation of the signal covariance matrix requires more effort.

First of all, we assume that the signal components $y_{1}, \ldots y_{6}$ associated with a particular spherical harmonic coefficient are not correlated with each other. This means that signal covariance matrix $\mathbf{S}^{(y)}$ has a block-diagonal structure and is composed of six blocks $\mathbf{S}_{m}^{(y)}(m=1, \ldots 6)$. The latter ones are estimated together with the filtered solutions in an iterative way. At each iteration, we consider three already available 2-year estimations $\mathbf{y}_{m}^{(k)}(k=1,2,3)$ of a particular signal component as three independent samples of the stochastic process $\mathcal{Y}_{m}$. Let $\mathbf{g}_{m}^{(k)}$ denote a vector representing the result of transforming the component $\mathbf{y}_{m}^{(k)}$ into the spatial domain. This resulting vector is defined as a set of Equivalent Water Layer Thicknesses (EWLT) at suitably chosen grid nodes. The signal variances $\operatorname{diag}\left(\mathbf{S}_{m}^{(g)}\right)$ in the spatial domain are then estimated as

$\operatorname{diag}\left(\mathbf{S}_{m}^{(g)}\right)=\frac{1}{3} \sum_{k=1}^{3} \operatorname{diag}\left(\mathbf{g}_{m}^{(k)}\left(\mathbf{g}_{m}^{(k)}\right)^{\mathrm{T}}\right)$.

Signal covariances in the spatial domain, i.e., the off-diagonal elements of $\mathbf{S}_{m}^{(g)}$, are set equal to zero. Let $\mathbf{Y}$ be the matrix of spherical harmonic analysis, which converts a function specified on the grid into the appropriate set of spherical harmonic coefficients. Then, the diagonal signal covariance matrix $\mathbf{S}_{m}^{(g)}$ is propagated into a full covariance matrix in the domain of spherical harmonic coefficients as follows:

$\mathbf{S}_{m}^{(y)}=\mathbf{D} \mathbf{Y} \mathbf{S}_{m}^{(g)} \mathbf{Y}^{\mathrm{T}} \mathbf{D}$, where $\mathbf{D}$ is a diagonal matrix, defined by

$\mathbf{D}_{j, j}=\frac{1}{l_{j}} \times \frac{3\left(1+k_{l_{j}}\right) \rho_{\mathrm{w}}}{R\left(2 l_{j}+1\right) \rho_{\mathrm{e}}}$.

Herein, $l_{j}$ is the degree of the spherical harmonic coefficient associated with the $j$ th element of the vector $\mathbf{y}_{m}^{(k)}$, $k_{l_{j}}$ is the load Love number of degree $l_{j}, \rho_{\mathrm{w}}$ is the density of water $\left(1,000 \mathrm{~kg} / \mathrm{m}^{3}\right)$ and $\rho_{\mathrm{e}}$ is the average density of the Earth (approximately $5,500 \mathrm{~kg} / \mathrm{m}^{3}$ ). The factor $l_{j}^{-1}$ in front of the term on the right-hand side of Eq. (10) compensates for the neglection of covariances in the spatial domain by forcing a smoothness of the signal (Klees et al. 2008; Liu et al. 2010). The rest of the right-hand side of Eq. (10) reflects the change in the signal representation: from EWLT in the spatial domain to dimensionless spherical harmonic coefficients in the spectral domain (Wahr et al. 1998).

As soon as the signal covariance matrix is assembled and the optimal filter is computed with Eq. (6), the filtered solutions $\mathbf{z}_{m}^{(k)}$ at the given iteration are produced. Then, they are used as the input to estimate the signal covariance matrix at the next iteration.

The iterations start from the assumption that the signal variances of all the components are constant in the spatial domain. A sufficient number of iterations is performed in order to guarantee the convergence of the procedure. For instance, the average difference between the trend signal variances at two last iterations is kept at the level of $0.2 \%$ (with the peak values being below $4 \%$ ).

The initial values of signal variances adopted in our case are $1 \mathrm{~m}^{2}$ for the bias, annual and semi-annual components, and $1 \mathrm{~m}^{2} /$ year ${ }^{2}$ for the trend component. To quantify the potential effect of this particular choice, we performed a number of test computations to spherical harmonic degree 60 , the initial signal variances being changed in a range spanning 8 orders of magnitude $\left(10^{-4}-10^{4} \mathrm{~m}^{2} / \mathrm{year}^{2}\right.$ and $10^{-4}-10^{4} \mathrm{~m}^{2}$ for the trend and other components, respectively). It turned out that the results are sufficiently robust against the choice of the initial signal variances. In particular, the trend estimates for Greenland and surrounding areas were different by less than $0.2 \mathrm{~mm} /$ year. Such a difference is about 3 orders of magnitude smaller than the expected signal and, therefore, would have a negligible effect on the estimates obtained. This conclusion is fully consistent with the findings of Klees et al. (2008), who applied a similar filtering procedure in the context of monthly solutions.

Unfortunately, the procedure described above leads to a contamination of the bias component $\mathbf{y}_{1}^{(k)}$ with strong concentric ringing artifacts around the poles. The same effect has been also observed by Liu et al. (2010) when they applied the optimal filter to monthly solutions. In order to eliminate these artifacts, we artificially suppress at each iteration the 
bias signal variances near the poles, using a procedure similar to that described by Liu et al. (2010).

\subsubsection{Restoring continuity}

The processing strategy described above yields the sets of filtered parameters:

$$
\left(\mathbf{z}^{(k)}\right)^{\mathrm{T}}=\left[\left(\mathbf{z}_{1}^{(k)}\right)^{\mathrm{T}} \ldots\left(\mathbf{z}_{6}^{(k)}\right)^{\mathrm{T}}\right] \quad(k=1,2,3)
$$

for all three 2-year time intervals under consideration. Substitution of the obtained components $\mathbf{z}_{m}^{(k)}$ into Eq. (1) in place of $\mathbf{y}_{m}^{(k)}$ leads to filtered observations $\mathbf{x}^{(k)}\left(\tau^{(k)}\right)$. A formal catenation of $\mathbf{x}^{(k)}\left(\tau^{(k)}\right)(k=1,2,3)$ results in discontinuities at the joint points of the 2-year time intervals, i.e.,

$\mathbf{x}^{(k)}(1) \neq \mathbf{x}^{(k+1)}(-1) \quad(k=1,2)$,

which is inconsistent with the reality. To restore the continuity, we execute a second least-squares adjustment at the third processing stage. We update all the spherical harmonic coefficients in order to satisfy the conditions

$\tilde{\mathbf{x}}^{(k)}(1)-\tilde{\mathbf{x}}^{(k+1)}(-1)=0 \quad(k=1,2)$.

The covariance matrices of $\mathbf{z}^{(k)}$ are taken into account in order to find the optimal solution in the presence of the intrinsic non-uniqueness of the problem. Details of the second least-squares adjustment are presented in Appendix A. We denote the results of the second least-squares adjustment by

$\left(\mathbf{w}^{(k)}\right)^{\mathrm{T}}=\left[\left(\mathbf{w}_{1}^{(k)}\right)^{\mathrm{T}} \ldots\left(\mathbf{w}_{6}^{(k)}\right)^{\mathrm{T}}\right]$.

\subsection{6-year estimations}

In estimating the mass change parameters over the entire 6-year time interval, we extend the analytical function given by Eq. (1) with a quadratic (acceleration) term. This is motivated, in particular, by the results of Velicogna (2009), who found that the mass balance of the Greenland ice sheet is better represented when the acceleration term is included. The extended analytical function reads:

$$
\begin{aligned}
\mathbf{x}(\tau)= & \mathbf{y}_{1}+\mathbf{y}_{2} \tau+\mathbf{y}_{3} \cos (2 \pi \tau)+\mathbf{y}_{4} \sin (2 \pi \tau) \\
& +\mathbf{y}_{5} \cos (4 \pi \tau)+\mathbf{y}_{6} \sin (4 \pi \tau)+\mathbf{y}_{7} \tau^{2} .
\end{aligned}
$$

Now, we have only one sample $\mathbf{y}^{(k)}$ of the parameters $\mathbf{y}$. Since it is not possible to estimate signal variances from only one signal sample reliably, we compute them on the basis of the 2-year signal estimates. More specifically, the vector $\mathbf{g}_{m}^{(k)}$ is obtained in this case by transforming the components $\mathbf{w}_{m}^{(k)}$ estimated at the third processing stage into the spatial domain. Then, the signal variances in the spatial domain are obtained according to Eq. (8). A special case is the quadratic term, which is not estimated for 2-year time intervals.
One way to derive this term is to apply the double numerical differentiation to the 2-year bias estimates:

$\mathbf{g}_{7}=\frac{\mathbf{g}_{1}^{(1)}-2 \mathbf{g}_{1}^{(2)}+\mathbf{g}_{1}^{(3)}}{(2 T)^{2}}$.

However, as it was already pointed out, it is impossible to obtain a reliable estimate of the signal variance from only one signal sample. Therefore, we introduce also the second way to estimate the quadratic term: by the first-order numerical differentiation of the trend estimates:

$\mathbf{g}_{7}^{\prime}=\frac{1}{2} \sum_{k=1}^{2} \frac{\mathbf{g}_{2}^{(k+1)}-\mathbf{g}_{2}^{(k)}}{2 T}$.

In practice, the signal variance associated with the quadratic term is derived as the mean of the estimations based on the signals obtained in both ways:

$\operatorname{diag}\left(\mathbf{S}_{7}^{(g)}\right)=\frac{1}{2}\left(\operatorname{diag}\left(\mathbf{g}_{7}\left(\mathbf{g}_{7}\right)^{\mathrm{T}}\right)+\operatorname{diag}\left(\mathbf{g}_{7}^{\prime}\left(\mathbf{g}_{7}^{\prime}\right)^{\mathrm{T}}\right)\right)$.

\subsection{Fine tuning: suppression of ringing artifacts}

When signals with sharp edges are approximated by spherical harmonics, ringing artifacts occur, which is also known as the Gibbs phenomenon. Ringing artifacts can be observed, in particular, at the southeast coast of Greenland in the map of 6-year trends (Fig. 2). Since these artifacts are characterized by high spatial frequencies, they cannot significantly change the mean mass change in a region (at least, if the size of the region is sufficiently large). Nevertheless, we find that their presence makes the interpretation of the maps more difficult. Therefore, we perform a "fine-tuning" of the produced trend estimates by applying a variant of the fan filter (Zhang et al. 2009):

$$
\left\{\begin{array}{c}
\Delta C_{l m}^{(f)} \\
\Delta S_{l m}^{(f)}
\end{array}\right\}=\operatorname{sinc}\left(\frac{m}{l_{\max }}\right) \operatorname{sinc}\left(\frac{l}{l_{\max }}\right)\left\{\begin{array}{c}
\Delta C_{l m} \\
\Delta S_{l m}
\end{array}\right\},
$$

where $\Delta C_{l m}$ and $\Delta S_{l m}$ are spherical harmonic coefficients of an original trend estimate, $\Delta C_{l m}^{(f)}$ and $\Delta S_{l m}^{(f)}$ are the filtered spherical harmonic coefficients, and $\operatorname{sinc}(x)=$ $(\pi x)^{-1} \sin (\pi x)$. For a maximum spherical harmonic degree $l_{\max }=120$, this filter is comparable to a Gaussian filter with a half-width of $140 \mathrm{~km}$. We favor the fan filter given by Eq. (19) due to its direct linkage to the maximum spherical harmonic degree.

Since the spatial resolution of GRACE-based solutions is, at best, of the order of $300 \mathrm{~km}$, the application of the fan filter introduced above can be considered as a minor cosmetic change. The effect of the filter on the trend estimates in the area of Greenland is shown in Fig. 2. It should be noted that suppressing ringing artifacts slightly increases signal blurring. 


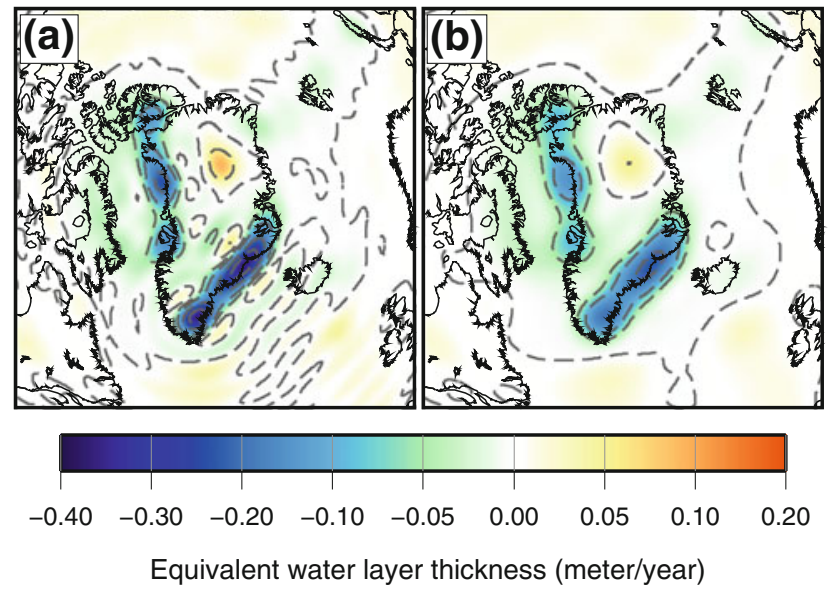

Fig. 2 Effect of the filter for suppressing ringing artifacts. Shown is the estimated trend for the 6-year time interval $\mathbf{a}$ before and $\mathbf{b}$ after applying the fan filter for suppressing ringing artifacts. The trend is corrected for GIA

\section{Case study: mass change trends in Greenland and the neighbouring regions}

This section is subdivided into five parts. In the first part, we present the actual data we used as the input. The second part is concerned with the comparison of the trends estimated as proposed above and the trends derived from the DMT-1 model, which is composed of optimally filtered monthly solutions. The focus of the comparison lies on the difference in spatial resolution. In the third part, we analyze the temporal variability of the estimated 2-year trends. In the fourth part, we investigate the mass balance of the Greenland ice sheet as a whole and of its individual drainage systems defined according to Zwally et al. (2005). Finally, we compare our estimates with those obtained by other authors on the basis of both GRACE data and other sources of information.

The number of the considered drainage systems is six. A similar division has also been used by other authors in the context of GRACE-based mass balance estimations (Luthcke et al. 2006a; Slobbe et al. 2009; Wouters et al. 2008). In addition, we estimate the mass balance for four regions associated with the islands surrounding Greenland (cf. Fig. 3):

- Region "ED": Ellesmere and Devon Island (together with adjacent islands of smaller size)

- Region "B": Baffin Island (together with adjacent islands)

- Region "I": Iceland

- Region "S": Svalbard.

Thus, we provide mass balance estimates for ten regions inside and around Greenland.

\subsection{Input data}

The data used in this study are collection of unconstrained monthly gravity field solutions complete to spherical harmonic degree and order 120, including their covariance matrices, in the time interval 2003-2008 (excluding January 2003 and June 2003). Each solution represents the mean monthly deviation of the gravity field from the long-term mean gravity field defined by the EIGEN-GL04C model (Förste et al. 2008). Those solutions were produced at the Delft University of Technology (TUD) on the basis of GRACE KBR data as well as precise GRACE orbits computed at TUD and at the GNSS Research and Engineering Center of Wuhan University. Nuisance time-varying signals associated with tides, as well as with non-tidal mass transport in the ocean and atmosphere, were eliminated on the basis of appropriate models. In particular, the FES2004 model (Lyard et al. 2006) was used to model ocean tide signal. An original data processing methodology was exploited that can be considered as a variant of the acceleration approach. The methodology included, among other, the application of frequency-dependent data weighting based on a realistic noise power spectral density. Thus, the covariance matrices accompanying the exploited monthly solutions can be considered as a sufficiently accurate stochastic description of the solution errors.

Further description of the utilized unconstrained solutions can be found in Liu (2008) and Liu et al. (2010). It is worth adding that these solutions were also used for the production of the DMT-1 model (Liu et al. 2010).

The total mass balance derived from GRACE data reflects the sum of all geophysical processes associated with mass transport in the study region, including the GIA. In order to correct the obtained estimates for the GIA signal, we compute mass changes on the basis of the ICE-5G (VM2) model (Peltier 2004) up to degree and order 120. Then, the GIA signal is subtracted from the unconstrained monthly solutions prior to their processing. We present estimates of the mass balance produced both with and without the GIA correction.

\subsection{6-year trends and their spatial resolution}

The methodology described in Sect. 2 has been applied to obtain the optimally filtered estimations of all seven signal components given by Eq. (15). The global maps of the mass change trends, obtained both without and with GIA correction, are shown in Fig. 4. The GIA correction causes only minor changes in the trends in the area of Greenland. However, in some other areas (e.g., in North Canada and Fennoscandia) this correction reduces the observed positive trends significantly. In the presence of signal leakage due to a limited spatial resolution of the obtained solutions, the 

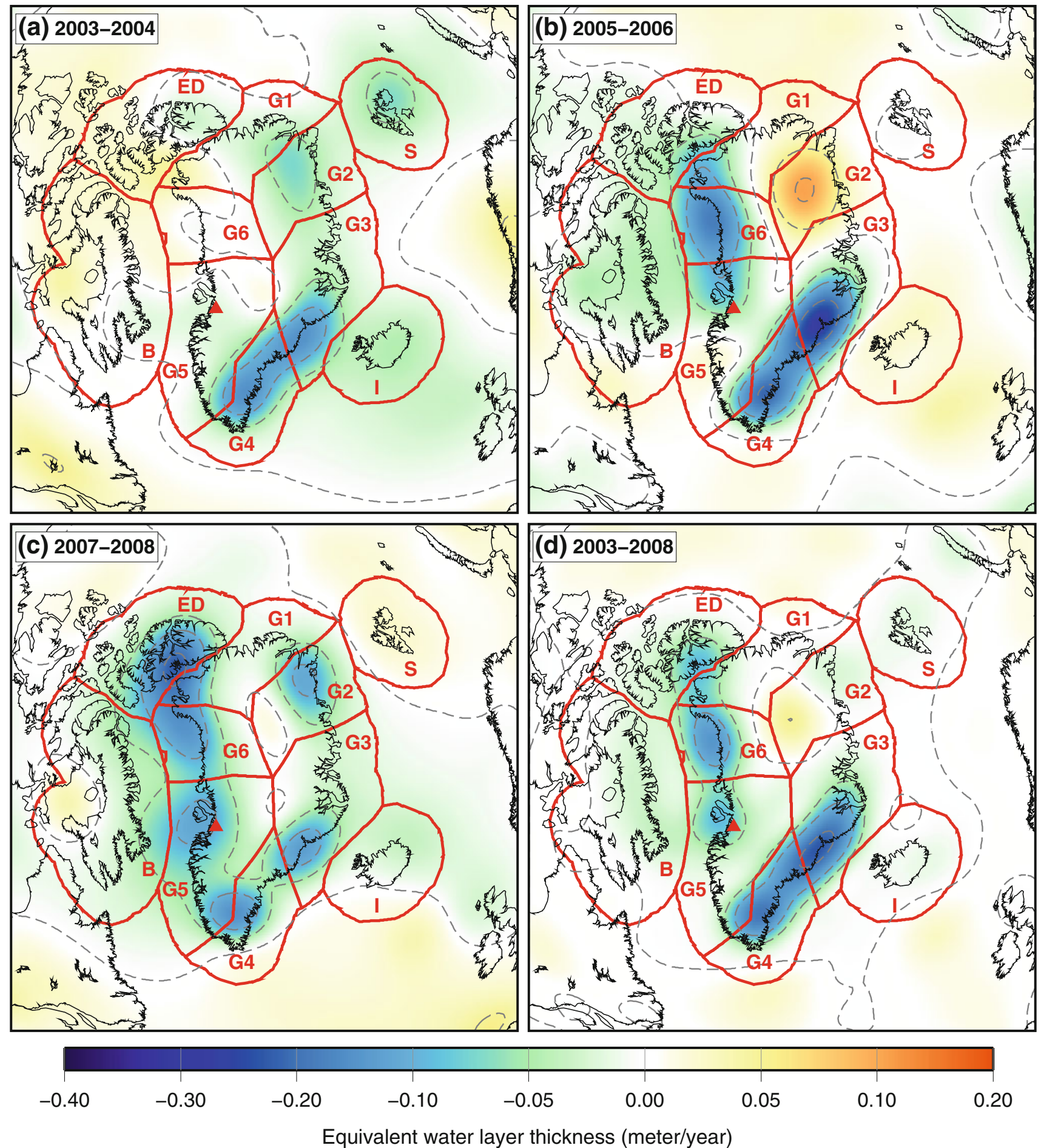

Fig. 3 Estimated trends in a 2003-2004, b 2005-2006, c 2007-2008 and d 2003-2008. The trends are corrected for GIA. The regions marked by red lines are Greenland's drainage systems one to six (G1-G6),

Ellesmere Island and Devon Island $(E D)$, Baffin Island $(B)$, Svalbard $(S)$ and Iceland (I). Red triangles denote the Jakobshavn Glacier

application of the GIA correction is essential for an accurate estimation of ice mass variations in Greenland and the surrounding islands.

The high spatial resolution of the trend signal obtained with the new procedure is especially obvious in the areas with a strong spatial gradient of the trends, like Greenland. 


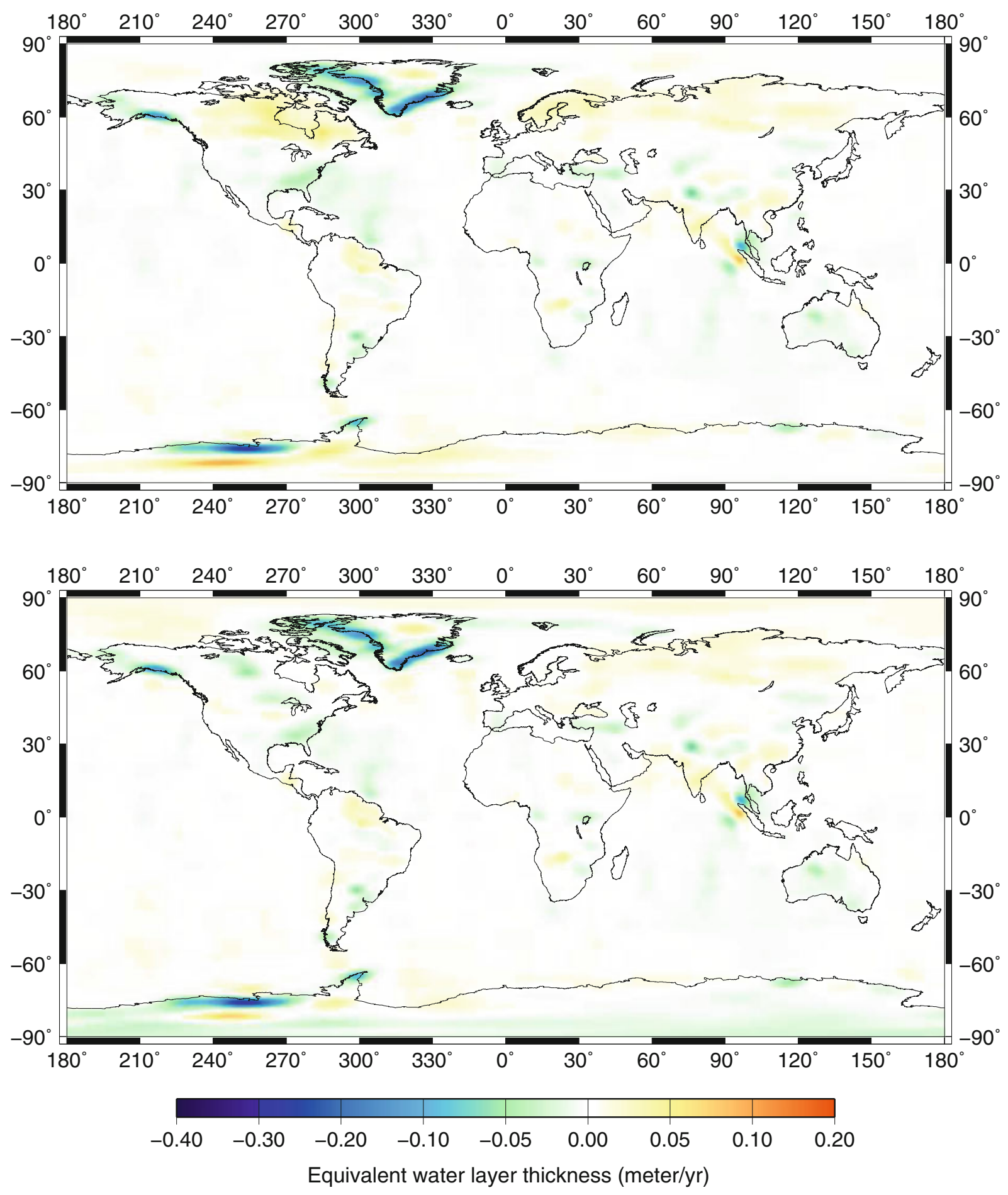

Fig. 4 Global maps of the estimated mass change trends in 2003-2008, without (top) and with (bottom) GIA-correction

For a comparison, we have directly derived mass change trends from the filtered monthly solutions comprising the DMT-1 model, the seven-parameter analytical function being used (Fig. 5). The difference between the obtained trend distributions is largest at the west coast of Greenland. The trend based on the DMT-1 model shows only one region of mass loss at the north part of the west coast, while the trend estimated using the new procedure identifies three different regions of mass loss: one centered near Jakobshavn Glacier, one located at the northwest coast of Greenland, and one at the east coast of Ellesmere Island. Furthermore, the amplitude of the mass loss signals at the west coast of Greenland 


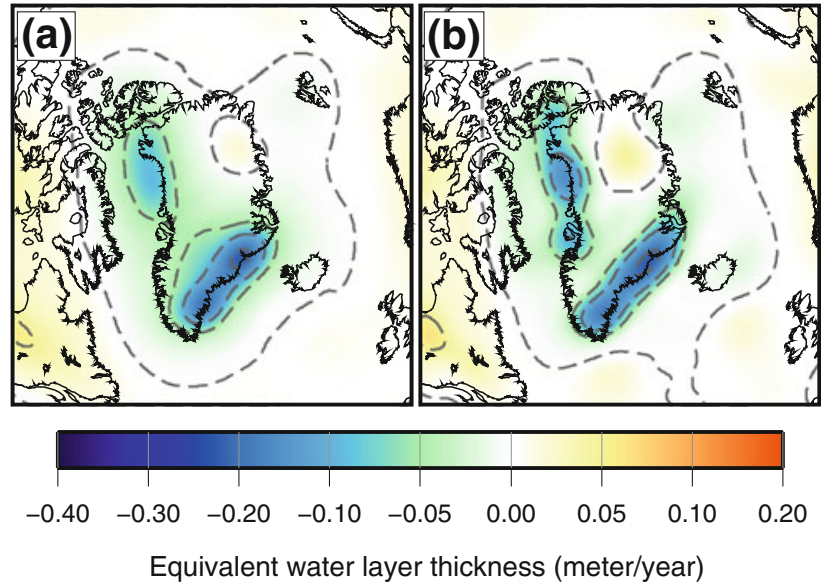

Fig. 5 Demonstration of the difference in spatial resolution of a the trend based on the filtered monthly solutions from the DMT-1 model and $\mathbf{b}$ the trend estimated using the methodology described in Sect. 2. Shown are the estimated trends in 2003-2008. The trends are not corrected for GIA

is about two times larger when the new filtering procedure is applied. In both trend maps we can see also mass loss signals all along the southeast coast of Greenland. While in this case the amplitudes are similar for both estimates, the signal obtained with the new filtering procedure is sharper and more stretched along the coast.

Besides differences in signal amplitudes and sharpness, we can also observe some offsets in the signal locations. The best example is the small mass gain in the northern part of Greenland. In the trend derived from the DMT-1 model the mass gain signal is located further to the east than in the trend estimated with the new filtering procedure. This phenomenon can be explained in the following way. When a positive and negative mass change signals are located close to each other, filtering slightly shifts these signals apart from each other. Since the filter applied to the monthly solutions was more aggressive (caused a heavier smoothing) than the new one, the shift in the former case is larger.

\subsection{Temporal variability}

The estimation of trends for the three subsequent 2-year time intervals allows the temporal variability of mass losses to be investigated. In the plots $\mathrm{a}, \mathrm{b}$, and $\mathrm{c}$ in Fig. 3, we show the trends obtained for the 2-year intervals 2003-2004, 2005-2006 and 2007-2008, respectively, corrected for the GIA signal. The comparison reveals that these trends are characterized by a large variability from interval to interval. Even though this is to be expected, the magnitude of the interannual variations is surprisingly large. This implies that the 6-year trends, which represent the average mass changes in 2003-2008 (Fig. 3d) may look very differently when another time interval is considered. In other words, any trend estimate is heavily dependent on the time interval under consideration, even the duration of the interval is relatively long.

The largest variability can be observed in region $\mathrm{G} 2$ at the northeast coast of Greenland. While in 2003-2004 a mass loss can be observed there, the interval 2005-2006 shows a prominent mass gain. In 2007-2008, we see again a mass loss signal, the amplitude of which being twice as large as in 2003-2004. The second largest variability can be observed at the west coast of Greenland. In 2003-2004, we cannot identify any large mass change there. In 2004-2005, we observe a noticeable mass loss signal with the center at the northwest coast (region G6), stretching from Jakobshavn Glacier to the east coast of Ellesmere Island. In 2007-2008, we can see two clearly separated mass loss signals: one at Jakobshavn Glacier and the other one stretched from the northwest coast in region G6 to the west coast of Ellesmere Island, where the maximum mass loss is observed. This implies that a strong signal leakage from region ED into region G1 may exist. The southeast coast of Greenland shows mass loss signals in all three time intervals. Here, the temporal variability affects only the amplitude of the signal, which is largest in 20052006. This is the area in which the average rate of mass loss is the largest. In addition, we note that the northern coast of Greenland appears to be stable throughout the considered 6 -year time interval. Finally, we observe a prominent mass loss signal over Svalbard in 2003-2004.

\subsection{Mass balance estimation}

We have used the obtained trend distributions to quantify the mass balance for the regions under consideration. To that end, the spatial distributions of trends are integrated over the target regions. In order to compensate for signal leakage, we introduce buffer zones around Greenland and other islands. The chosen buffer zone width reaches $300 \mathrm{~km}$. According to Fig. 6, this width is sufficient because the mass balance estimations do not change much as soon as this width is reached. It should be noted that the actual width of some buffer zones is less than $300 \mathrm{~km}$, so that overlapping regions are avoided (cf. Fig. 3).

Even though we use buffer zones, a minor signal leakage from a target region still may occur (especially where the buffer width is reduced with respect to the nominal value of $300 \mathrm{~km}$ ). For this reason, we compute appropriate scaling factors and apply them to the mass balance estimates. We would like to stress that only the quantitative estimates given in Table 1 are subject to this scaling. Since we compute mass balance estimates with and without a correction for the GIA signal, and consider four time intervals (i.e., 2003-2004, 2005-2006, 2007-2008 and 2003-2008), eight different scaling factors per region are produced. In the first instance, we compute scaling factors for five regions: 


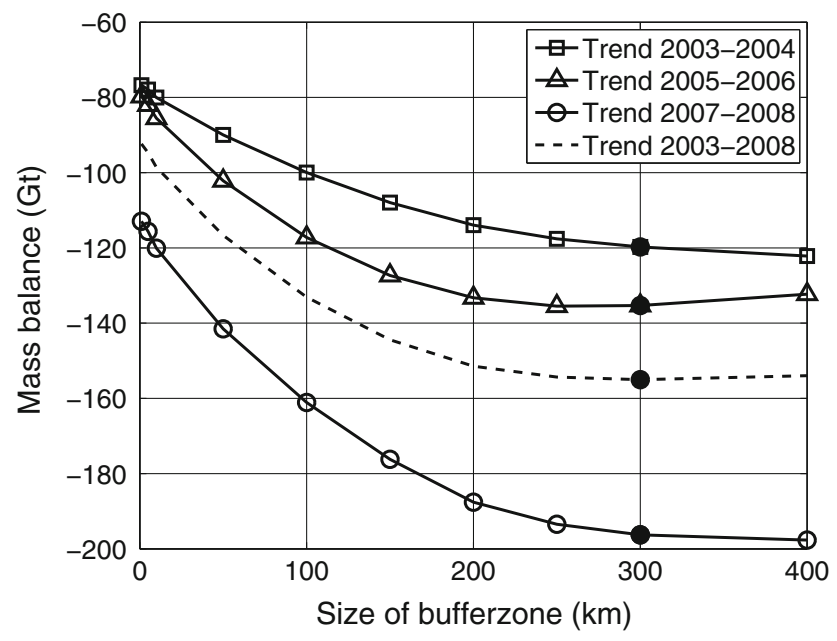

Fig. 6 Dependence of the mass balance of the entire Greenland ice sheet on the width of the buffer zone. Each mass balance estimate is corrected for GIA and not scaled

Greenland (as a whole) and four regions around it ("ED", "B", "S", and "I").

The scaling factors are obtained as follows. First, we construct a synthetic trend signal by clipping a $50 \mathrm{~km}$ wide band along the coasts out of the maps of the estimated trends (Fig. 3). The spatial distribution of trends within this band is taken over from the maps: the synthetic trend is large in the coastal areas where the mass loss is strong and low in the coastal areas where the mass loss is minor. Outside this band, we set the synthetic trend signal equal to zero. Such an approach is motivated by the results of radar altimetry surveys (Krabill et al. 2000, 2004), which show that the Greenland ice sheet is thinning near the coast and in balance at higher elevations. Our approach is slightly different from a more commonly used one, where a uniform distribution of the signal in the considered band is assumed (Velicogna et al. 2006). By clipping a band out of the maps of the estimated trends, we expect to obtain a more realistic synthetic trend because the mass loss is not a homogeneous process, and as such it does not influence all the coasts evenly. The chosen band width $(50 \mathrm{~km})$ is consistent with a typical width of the ablation zone, where most of mass losses occur. One may argue that the actual width of the ablation zone at some locations might be larger: up to $100 \mathrm{~km}$ or even more. It is necessary to keep in mind, however, that the spatial resolution of the maps used as the input is limited, so that any width in the range from 0 to $100 \mathrm{~km}$ would lead to very similar results.

Next, we subdivide the synthetic spatial distribution of trends into five parts, in accordance with the regions under investigation (Greenland and 4 regions around it). Each part is approximated by a spherical harmonic series to degree and order 120 . Then, we apply the Wiener-type filter and the filter for suppressing ringing artifacts to each set of spherical harmonic coefficients in the same way as is done with the coefficients based on real GRACE data. At this point, the signal components other than linear trends are set equal to zero. Finally, we compute the mass balance for each region from the filtered sets of spherical harmonic coefficients. The result is a matrix with five rows and five columns indicating, in particular, the amount of signal leakage from one region to another caused by the approximation with spherical harmonics and the subsequent filtering. If we arrange the matrix such that each column corresponds to one set of spherical harmonic coefficients, then the sum over one row gives the mass balance estimate (suffering from the signal leakage) for the given region. Then, the scaling factor for a region is obtained as the the ratio of the "true" mass balance (i.e., directly based on the synthetic trend signal) and the mass balance estimate derived from the filtered spherical harmonic coefficients.

In order to estimate the mass balance per Greenland's drainage system, we repeat the procedure described above, having identified ten regions (six drainage systems inside Greenland and four regions around it). The newly computed set of scaling factors plays an auxiliary role: it is applied to the individual drainage systems inside Greenland only. Of course, the sum of obtained mass balances per drainage system may not be equal to the mass balance of entire the Greenland ice sheet computed as described above. In practice, however, the observed discrepancies for all the time intervals under consideration are minor (within $6 \mathrm{Gt} / \mathrm{year}$ ). In order to eliminate even these minor discrepancies, we proportionally up- or down-scale the mass balances of individual drainage systems. This operation changes the mass balance estimates by $1-2 \mathrm{Gt} /$ year at maximum. It is also worth adding that both sets of scaling factors result in almost identical mass balance estimates for the islands around Greenland.

In this study, we do not consider signals and signal leakage associated with oceanic and atmospheric masses because their contribution to the ice mass balance is likely to be negligible (Velicogna 2009). Furthermore, we ignore the signal leakage caused by mass change trends of hydrological origin in the rest of the world because their contribution to the mass balance of the Greenland ice sheet does not exceed $6 \mathrm{Gt} / \mathrm{year}$ (Velicogna 2009); the other (smaller) regions are influenced by this signal leakage even less.

In our study, we also make an attempt to quantify the uncertainty of the produced mass balance estimates. We consider errors from four sources. The first is the random error of the estimated trends, which is a consequence of errors in the original GRACE data. We quantify this error by means of the formal error propagation with a subsequent scaling based on the variances estimated in the course of the adjustments. This procedure is similar to the one proposed by Wahr et al. (2006). The second error source is the uncertainty of the models used to correct for GIA. We estimate the uncertainty of these models by analyzing the effect 
Table 1 Mass balance per region and per time interval

\begin{tabular}{|c|c|c|c|c|c|c|c|c|}
\hline \multirow{2}{*}{$\begin{array}{l}\text { Time span } \\
\text { Region }\end{array}$} & \multicolumn{2}{|l|}{ 2003-2004 } & \multicolumn{2}{|l|}{ 2005-2006 } & \multicolumn{2}{|l|}{ 2007-2008 } & \multicolumn{2}{|l|}{ 2003-2008 } \\
\hline & $\begin{array}{l}\text { With GIA } \\
(\mathrm{Gt} / \mathrm{yr})\end{array}$ & $\begin{array}{l}\text { GIA- } \\
\text { corrected } \\
(\mathrm{Gt} / \mathrm{yr})\end{array}$ & $\begin{array}{l}\text { With GIA } \\
(\mathrm{Gt} / \mathrm{yr})\end{array}$ & $\begin{array}{l}\text { GIA- } \\
\text { corrected } \\
(\mathrm{Gt} / \mathrm{yr})\end{array}$ & $\begin{array}{l}\text { With GIA } \\
\text { (Gt/yr) }\end{array}$ & $\begin{array}{l}\text { GIA- } \\
\text { corrected } \\
(\mathrm{Gt} / \mathrm{yr})\end{array}$ & $\begin{array}{l}\text { With GIA } \\
(\mathrm{Gt} / \mathrm{yr})\end{array}$ & $\begin{array}{l}\text { GIA- } \\
\text { corrected } \\
(\mathrm{Gt} / \mathrm{yr})\end{array}$ \\
\hline G1 & $-4 \pm 3$ & $-5 \pm 3$ & $-2 \pm 4$ & $-3 \pm 5$ & $-21 \pm 22$ & $-22 \pm 22$ & $-7 \pm 5$ & $-8 \pm 6$ \\
\hline G2 & $-24 \pm 7$ & $-24 \pm 7$ & $25 \pm 6$ & $24 \pm 6$ & $-30 \pm 6$ & $-31 \pm 7$ & $5 \pm 2$ & $4 \pm 6$ \\
\hline G3 & $-47 \pm 10$ & $-44 \pm 9$ & $-56 \pm 7$ & $-55 \pm 8$ & $-45 \pm 7$ & $-44 \pm 8$ & $-55 \pm 4$ & $-54 \pm 5$ \\
\hline G4 & $-49 \pm 14$ & $-48 \pm 14$ & $-49 \pm 16$ & $-50 \pm 15$ & $-21 \pm 10$ & $-21 \pm 10$ & $-45 \pm 11$ & $-44 \pm 11$ \\
\hline G5 & $-10 \pm 11$ & $-8 \pm 12$ & $-25 \pm 12$ & $-22 \pm 12$ & $-60 \pm 16$ & $-58 \pm 16$ & $-37 \pm 6$ & $-35 \pm 7$ \\
\hline G6 & $0 \pm 4$ & $1 \pm 4$ & $-42 \pm 8$ & $-40 \pm 8$ & $-36 \pm 9$ & $-34 \pm 9$ & $-30 \pm 4$ & $-28 \pm 4$ \\
\hline Greenland (G1-G6) & $-134 \pm 11$ & $-129 \pm 15$ & $-150 \pm 14$ & $-146 \pm 17$ & $-213 \pm 27$ & $-209 \pm 29$ & $-169 \pm 10$ & $-165 \pm 15$ \\
\hline ED & $14 \pm 6$ & $9 \pm 5$ & $-15 \pm 4$ & $-18 \pm 5$ & $-60 \pm 15$ & $-64 \pm 15$ & $-18 \pm 3$ & $-22 \pm 4$ \\
\hline B & $33 \pm 8$ & $18 \pm 8$ & $-18 \pm 4$ & $-35 \pm 7$ & $-25 \pm 7$ & $-44 \pm 10$ & $-4 \pm 3$ & $-21 \pm 6$ \\
\hline $\mathrm{S}$ & $-24 \pm 2$ & $-28 \pm 3$ & $3 \pm 1$ & $-2 \pm 2$ & $12 \pm 2$ & $9 \pm 2$ & $-3 \pm 1$ & $-6 \pm 2$ \\
\hline I & $-34 \pm 6$ & $-33 \pm 6$ & $12 \pm 2$ & $13 \pm 3$ & $-25 \pm 6$ & $-24 \pm 8$ & $-12 \pm 2$ & $-17 \pm 9$ \\
\hline
\end{tabular}

Both the mass balance containing the GIA signal and the GIA-corrected ones are shown. All the numbers are scaled to compensate for signal leakage. The region abbreviations used: $G 1-G 6$ Greenland's drainage systems one to six, $E D$ Ellesmere Island and Devon Island, $B$ Baffin Island, $S$ Svalbard, I Iceland

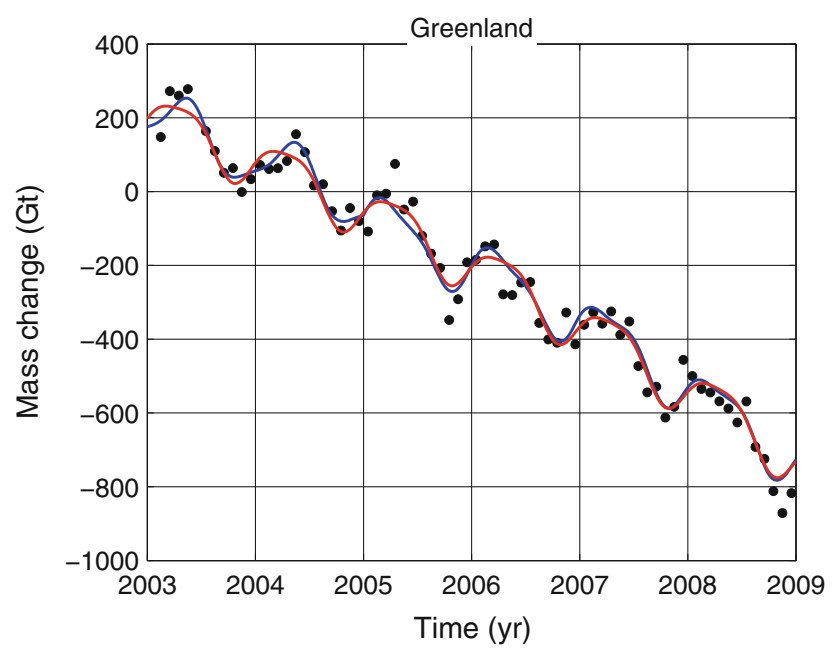

Fig. 7 Time series of mass changes integrated over the entire Greenland ice sheet. Shown are the estimated analytical function for the 6-year time interval ( $r e d$ ) and the 2-year time intervals (blue). For comparison, the mass changes based on the monthly solutions from the DMT-1 model are also shown (black dots). The GIA correction is applied

of compressibility, lateral heterogeneity and Earth rotation on the mass balance. Furthermore, we assume that the contribution of uncertainty in the ice history to the total GIA model uncertainty is approximately $50 \%$ (Velicogna et al. 2006). It is important to add that the errors of the first two types discussed above are ultimately scaled with the same factors as are used for scaling the mass balance estimates themselves. The third and fourth error sources are related to signal leakage from a region of interest to the outside and vice versa, respectively. In order to quantify this leakage, we use the aforementioned matrix showing the amount of signal leakage from one region to another. Using this matrix, it is straightforward to compute the total amount of leakage from a given region to the outside, as well as the leakage from all the other regions into the given one. The full signal leakage of both types is considered as an additional error in the resulting estimation, even though the applied scaling factors should compensate for the signal leakage. Thus, our estimation of errors of the latter two types is rather conservative.

Summarizing, the total error $\varepsilon$ in an estimated mass balance is obtained as follows:

$\varepsilon^{2}=f^{2}\left(\varepsilon_{\mathrm{GRACE}}^{2}+\varepsilon_{\mathrm{GIA}}^{2}\right)+\varepsilon_{\mathrm{IN}}^{2}+\varepsilon_{\mathrm{OUT}}^{2}$,

where $f$ is the scaling factor, $\varepsilon_{\text {GRACE }}$ is the formal error scaled by the variance factor, $\varepsilon_{\text {GIA }}$ reflects the uncertainty of the GIA model, and $\varepsilon_{\mathrm{IN}}$ and $\varepsilon_{\mathrm{OUT}}$ are the errors due to signal leakage from a given region to the outside and from the other regions into the given one, respectively.

Figure 7 shows the time series of mass changes integrated over the entire Greenland ice sheet. The most prominent feature is the strong mass loss. Table 1 shows that the rate of mass change integrated over Greenland and appropriately scaled was equal to $-165 \mathrm{Gt}$ /year in 2003-2008. Furthermore, the rate of mass loss increased from - $129 \mathrm{Gt} /$ year in 2003-2004 to $-209 \mathrm{Gt} /$ year in 2007-2008. Due to the presence of the quadratic term in the 6-year estimations, the resulting analytical function (red curve in Fig. 7) gives a proper description of this feature. However, the acceleration of the mass loss must not be interpreted as a homogeneous process influencing the entire Greenland ice sheet equally. It is rather a net outcome of a complex and inhomogeneous behavior of individual drainage systems. This can be seen from estimations of mass balance per drainage system. For instance, the west coast of Greenland was stable in 2003-2004: the mass loss in the regions G5 and G6 was only $7 \mathrm{Gt} /$ year 

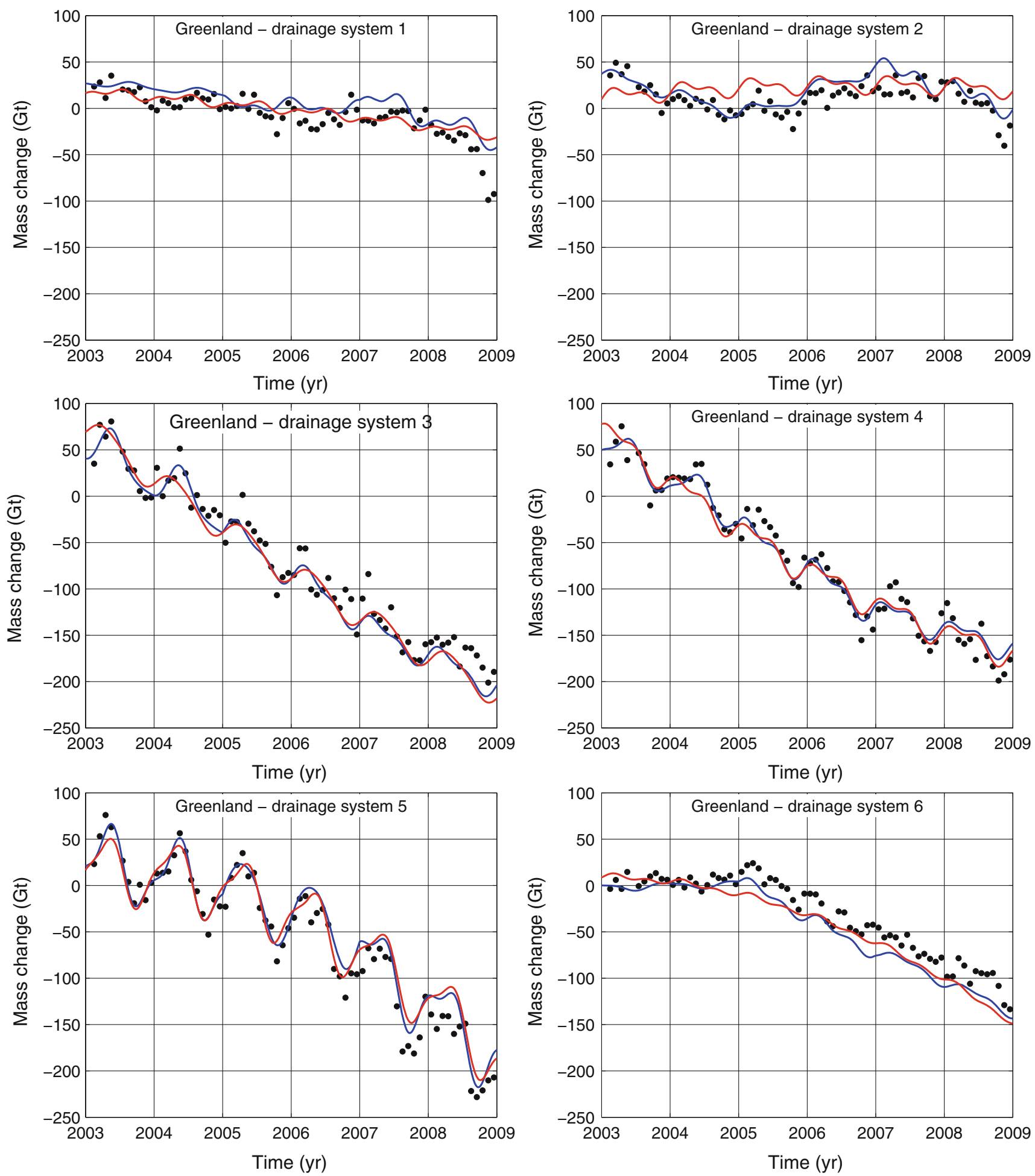

Fig. 8 Same as Fig. 7, but for the individual drainage systems of Greenland

(see Table 1). As a result, the mass loss of the entire Greenland ice sheet was smallest in that time interval. In 2005-2006, the mass loss in the regions G5 and G6 increased to $62 \mathrm{Gt} / \mathrm{year}$, which was, however, partly compensated by the mass gain of $24 \mathrm{Gt} /$ year in region G2. Nevertheless, the total mass loss of the Greenland ice sheet increased with respect to 2003-2004. In 2007-2008, the rate of mass loss in the regions G5 and G6 increased further (to $92 \mathrm{Gt} / \mathrm{year}$ ), which is in line with the results of Khan et al. (2010). Instead of compensating for this loss, region $\mathrm{G} 2$ also showed a negative trend of $31 \mathrm{Gt} /$ year. 

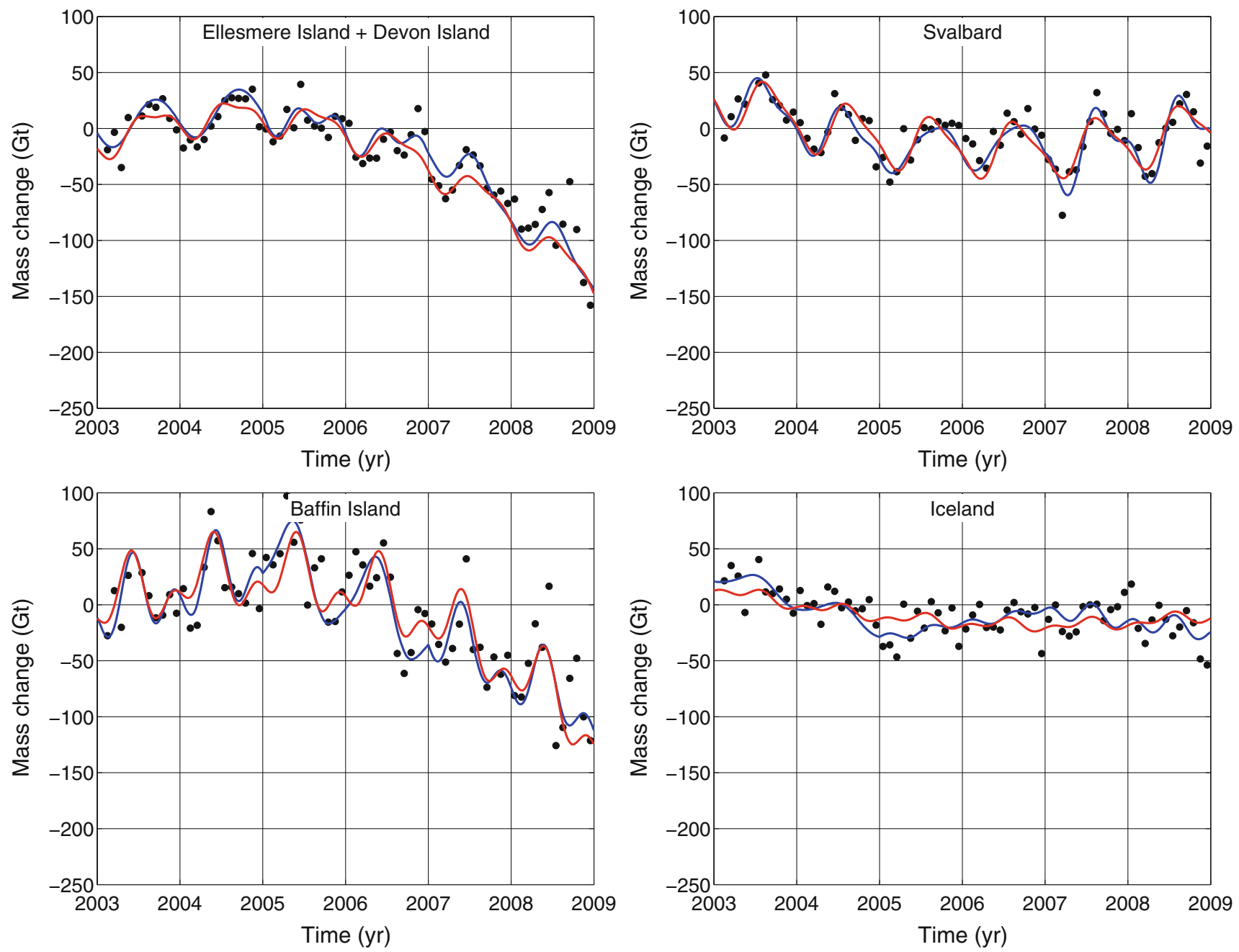

Fig. 9 Same as Fig. 7, but for the islands around Greenland

Thus, the mass loss of the entire Greenland ice sheet dramatically increased in 2007-2008 with respect to 2005-2006. It should be noted that the variability of the trends at the southeast coast of Greenland also affected the mass balance of the Greenland ice sheet.

The mass change time series for the individual drainage systems of Greenland and for the surrounding islands are shown in Figs. 8 and 9, respectively. One can see that all drainage systems of Greenland showed a different behavior, except for G3 and G4. The most complex behavior can be observed in regions G2 and G6. Region G2 appears to be relatively stable, with a positive trend in 2005-2006, which results in a small but positive mass balance in the entire 6-year time interval under consideration, even though the trends in 2003-2004 and 2007-2008 were negative. Region G6 was stable in 2003-2004, but had a negative mass balance thereafter, which is consistent with the observations by Khan et al. (2010). This change in behavior is translated into a mass loss acceleration described by the quadratic term in the analytical function covering the 6-year time interval. The regions belonging to the Canadian Arctic Archipelago ("ED" and "B") show an acceleration of mass loss, which is in agreement with the results of Gardner et al. (2011). Svalbard and Iceland demonstrate a noticeable mass loss in 2003-2004 with a tendency to stabilize thereafter.

Figures 7,8 and 9 also provide a comparison of the obtained time series to the mass changes derived from the DMT-1 model (black dots). While there is a good agreement between the time series for the entire Greenland ice sheet, we can observe systematic discrepancies between them for most of the smaller regions. Such a discrepancy is especially noticeable for region G6, where the new model shows in 2005-2008 systematically lower numbers than DMT-1. We explain the observed difference by a higher spatial resolution of the new estimates. The region G6 experienced a rapid mass loss in 2005-2008, which is clearly visible in the new model (Fig. 3b, c). The map of 6-year mass changes shows even a sharper image of a mass loss feature centered exactly 
in the middle of this region (Fig. 3d). This feature is poorly resolved by DMT-1 (see Fig. 5). Apparently, the latter model partly attributes mass loss in G6 to the neighbouring regions (G5 and G1).

On the other hand, some differences between the new model and DMT-1 may reflect the presence of interannual variations that cannot be described by the adopted analytic functions Eqs. (1) and (15). For instance, for the second half of 2007, when record ice melt in Greenland occurred, the DMT-1 model systematically shows a slightly lower total mass than the new model (Fig. 7). Thus, results obtained with the proposed filtering technique should be interpreted with caution when short-term mass changes are the primary focus.

\subsection{Mass balance estimates by other authors}

First of all, we find it essential to compare the obtained estimates of the mass balance of Greenland ice sheet with the numbers obtained by other authors on the basis of GRACE data. It should be noted that the previous publications, except for Wouters et al. (2008) and Schrama and Wouters (2011), did not make an attempt to distinguish explicitly between mass losses in Greenland and the surrounding regions. Therefore, it is likely that the previous estimations implicitly included (at least, partly) mass losses in the surrounding regions due to a limited spatial resolution of the mass change models. In an attempt to make the comparison more fair, we have summed up our estimations of mass change rates over Greenland and the Canadian Arctic Archipelago (regions "ED" and "B"), because the latter ones show mass losses at the locations near the west coast of Greenland (see also Gardner et al. 2011). Similarly, the estimates by Wouters et al. (2008) and Schrama and Wouters (2011) are shown as the sum "Greenland"+"Ellesmere Island" and "Greenland"+"Ellesmere Island"+"Baffin Island", respectively (Wouters et al. 2008 did not provide an estimate for Baffin Island). From Table 2, one can see a good consistency between our estimates and the previous ones (especially, if the two extremes, -88 and $-274 \mathrm{Gt} /$ year, are disregarded). It is also worth pointing out that the shown numbers correspond to slightly different time intervals. Differences between the numbers may reflect not only estimation errors but also the acceleration of the ice mass loss in recent years. This acceleration may explain a relatively low number obtained by Wouters et al. (2008) and a relatively high number presented by Schrama and Wouters (2011).

Secondly, we provide a comparison of our results with previous ones for individual regions: Ellesmere Island, Baffin, Svalbard, Iceland, and Greenland. In this comparison we refer to the numbers obtained in three different ways: from GRACE data, from ICESat data, and using the mass balance modeling (see Table 3). One can see that our mass balance estimates for Ellesmere Island, Baffin Island, Svalbard and Iceland are in a good agreement with the GRACE-based numbers from Wouters et al. (2008) and Schrama and Wouters (2011) (except for the mass balance for Baffin Island, but that number is estimated by Schrama and Wouters 2011 with a large uncertainty). Furthermore, our estimate of the mass balance of Baffin Island is in good agreement with the estimates obtained by Gardner et al. (2011) on the basis of GRACE and ICESat data. For Ellesmere Island, however, the estimates obtained by Gardner et al. (2011) using all three methods mentioned above are characterized by $50-100 \%$ higher values than those in our case. To a certain extent, this can be explained by an inconsistency of the considered time intervals (2004-2009 vs. 2003-2008 in our study) combined with a still accelerating ice mass loss in Ellesmere Island. A limited spatial resolution of GRACE-based models, including ours, may have also played a role, so that a part of the signal from Ellesmere Island is erroneously attributed in our case to the region G1 of Greenland. The mass balance of the Greenland ice sheet obtained in our study is noticeably lower than those presented by other authors. In particular, this concerns the estimates obtained in alternative ways: on the basis of ICESat data (Sørensen et al. 2011) and with the mass balance method (van den Broeke et al. 2009). These discrepancies show the need of further efforts aimed at better understanding the limitations of the techniques used for the estimation of ice mass changes.

\section{Conclusions}

In this paper, we have presented a new filtering procedure for post-processing GRACE-based monthly gravity field solutions provided in the form of spherical harmonic coefficients. The procedure is tuned for the optimal estimation of linear trends and other signal components that show a systematic behavior over long time intervals. The key element of the developed procedure is the statistically optimal Wiener-type filter which makes use of the full noise and signal covariance matrices. We would like to stress that the developed filter can be applied to an unconstrained GRACE-based model of temporal gravity field variations produced by any data processing center, provided that the full covariance matrices of errors in the produced solutions are available.

We have shown that the maps of mass change trends obtained with the new filter show a significantly higher spatial resolution than those derived from the DMT-1 model. Though the monthly solutions in that model were also optimally filtered, the filter applied in that case was tuned to produce best monthly estimations and, therefore, was more aggressive than the one applied in this study. This is because linear trends and other systematic signal components are estimated on the basis of a long-term (in our case, 6-year) 
Table 2 Some recent GRACE-based estimations of the mass balance of the Greenland ice sheet together with (presumably) surrounding regions

\begin{tabular}{llll}
\hline Author & GRACE model & Time span & Mass balance (Gt/year) \\
\cline { 3 - 4 } & & & With GIA \\
\hline Wouters et al. (2008) $^{\mathrm{a}}$ & CSR & February 2003-January 2008 & $-195 \pm 34$ \\
Baur et al. (2009) & CSR & August 2002-July 2008 & $-221 \pm 13$ \\
Baur et al. (2009) & GFZ & August 2002-July 2008 & $-178 \pm 22$ \\
Baur et al. (2009) & JPL & August 2002-July 2008 & $-88 \pm 21$ \\
Velicogna (2009) & CSR & April 2002-February 2009 & $-274 \pm 6$ \\
Baur and Sneeuw (2011) & CSR & April 2002-March 2009 & $-230 \pm 33$ \\
Schrama and Wouters (2011) & CSR, GFZ, ITG & March 2003-February 2010 & $-191 \pm 16$ \\
This study & DEOS & February 2003-December 2008 & $-208 \pm 25$ \\
\hline
\end{tabular}

The ice density of $917 \mathrm{~kg} / \mathrm{m}^{3}$ was used to convert volume changes into mass changes when necessary. The column "GRACE model" contains information about the processing center that produced the GRACE-based model which was used as the input for the mass balance analysis: CSR Center of Space Research of the university of Texas at Austin, GFZ GeoForschungsZentrum Potsdam, JPL Jet Propulsion Laboratory of the California Institute of Technology, ITG Institute of Theoretical Geodesy of the University of Bonn, DEOS Delft Institute of Earth Observation and Space Systems of the Delft University of Technology

a Together with Ellesmere Island

$\mathrm{b}$ Together with Ellesmere and Baffin Island

${ }^{\mathrm{c}}$ Together with the islands of the Canadian Arctic Archipelago

Table 3 Comparison of mass balance estimations for Greenland and surrounding islands individually (Gt/year, the GIA signal is corrected for in case of GRACE-based estimates)

\begin{tabular}{|c|c|c|c|c|c|c|c|}
\hline \multirow[t]{2}{*}{ Author } & \multirow[t]{2}{*}{ Method/model } & \multirow[t]{2}{*}{ Time span } & \multicolumn{5}{|c|}{ Mass balance (Gt/year) } \\
\hline & & & Greenland & $\begin{array}{l}\text { Ellesmere } \\
\text { Island }\end{array}$ & $\begin{array}{l}\text { Baffin } \\
\text { Island }\end{array}$ & Svalbard & Iceland \\
\hline Zwally et al. (2011) & ICESat & 2003-2007 & $-171 \pm 4$ & & & & \\
\hline $\begin{array}{l}\text { Wouters et al. (2008) } \\
\text { Schrama and Wouters (2011) }\end{array}$ & $\begin{array}{l}\text { GRACE/CSR } \\
\text { GRACE/ CSR, } \\
\text { GFZ, ITG }\end{array}$ & $\begin{array}{l}\text { February 2003-January } 2008 \\
\text { March 2003-February } 2010\end{array}$ & $\begin{array}{l}-179 \pm 25 \\
-201 \pm 20\end{array}$ & $\begin{array}{l}-16 \pm 9 \\
-22 \pm 6\end{array}$ & $-11 \pm 15$ & $\begin{array}{l}-9 \pm 3 \\
-5 \pm 3\end{array}$ & $\begin{array}{l}-11 \pm 3 \\
-13 \pm 5\end{array}$ \\
\hline Sørensen et al. (2011) & ICESat & October 2003-March 2008 & $\begin{array}{l}-191 \pm 23 \\
-240 \pm 28\end{array}$ & & & & \\
\hline van den Broeke et al. (2009) & $\begin{array}{l}\text { Mass balance } \\
\text { modeling }\end{array}$ & January 2003-December 2008 & $-237 \pm 20$ & & & & \\
\hline Gardner et al. (2011) & $\begin{array}{l}\text { Mass balance } \\
\text { modeling }\end{array}$ & 2004-2009 & & $-34 \pm 13^{\mathrm{a}}$ & & & \\
\hline Gardner et al. (2011) & ICESat & 2004-2009 & & $-37 \pm 7^{\mathrm{a}}$ & $-24 \pm 6^{\mathrm{b}}$ & & \\
\hline Gardner et al. (2011) & GRACE/CSR & 2004-2009 & & $-39 \pm 9^{a}$ & $-24 \pm 7^{b}$ & & \\
\hline This study & GRACE/DEOS & February 2003-December 2008 & $-165 \pm 15$ & $-22 \pm 4^{\mathrm{a}}$ & $-21 \pm 6^{b}$ & $-6 \pm 2$ & $-17 \pm 9$ \\
\hline
\end{tabular}

${ }^{a}$ Together with the Devon Island and the other islands at the north of the Canadian Arctic Archipelago

$\mathrm{b}$ Together with the other islands at the south of the Canadian Arctic Archipelago

time series, which leads to a relatively low noise level that is taken into account in the computation of the noise covariance matrix.

We have applied the developed methodology to estimate the mass balance of the Greenland ice sheet, as well as the mass balance of its individual drainage systems, and of ice caps on the islands surrounding Greenland. We have observed that mass loss signals are located along the coast of Greenland, which is in agreement with other studies
(Abdalati et al. 2001; Wouters et al. 2008; Zwally et al. 2005). On the basis of 2-year estimates, we have found that the mass changes show a considerable variability over time. The largest variability is observed at the west coast of Greenland, while the north coast is the most stable region. Another prominent feature is the strong mass loss in 2007-2008 peaking on Ellesmere Island. It is important to add that our analysis confirms an accelerated mass loss in the territory of Greenland and Canadian Arctic Archipelago reported by 
Velicogna (2009) and Gardner et al. (2011), respectively. A quantitative comparison of our results with the GRACEbased results published earlier shows, in general, a good consistency between them. At the same time, our estimate of the mass balance of the Greenland ice sheet $(-165 \pm 15 \mathrm{Gt} / \mathrm{year})$ is somewhat lower than the numbers produced in alternative ways: from ICESat data and by the mass balance modeling. Further studies are needed in order to understand the causes of these discrepancies.

We would like to add that further development/tuning of the proposed technique might be needed, especially if other geographical locations are considered. First of all, further tuning can be needed if the mass change processes are characterized by a more complicated behavior in the time domain than assumed in this study. For instance, mass variations can be characterized by periods longer than 1 year or be aperiodic. Then, more than seven terms in the exploited analytic approximation in the time domain will be needed. There is, however, an obvious trade-off between the temporal and spatial resolution. In the present study, we reach a high spatial resolution, but are unable to give an adequate representation of rapid mass changes if they do not follow the adopted seven-parameter behavior. For instance, it is impossible to capture rapid mass loss in the region G1 in the second half of year 2008 (see Fig. 8a). Incorporation of more parameters would improve the ability of the proposed procedure to describe irregular mass variations, but, at the same time, would reduce the spatial resolution. Thus, the optimal choice of the analytic parameterization in the time domain must be made in each particular case individually.

Furthermore, one may find it reasonable to extend the proposed analytic approximation with the sinusoidal curve with the 161-day period in order to capture the residual $S_{2}$ tide signal that may alias into observed mass variations. We have not done this so far, assuming that this effect is small (at least, a visual inspection of Figs. 7, 8 and 9 does not reveal any evidence of such a signal). Our assumption is consistent with the findings of Chen et al. (2009), who demonstrated that the aliased $\mathrm{S}_{2}$ tide signal is indeed small, provided that a stateof-the art ocean tide model (e.g., FES2004) is used in the GRACE data processing. On the other hand, that publication also clearly shows that even the usage of the FES2004 model does not allow the $S_{2}$ tide signal to be sufficiently suppressed in some other areas (e.g., at the coasts of West Antarctica).

In addition, a better treatment of the ringing artifacts, which show up after the optimal filtering, is still advisable. These artifacts are mostly caused by localized anomalies, with a spectrum that spans a wide range of spherical harmonic degrees and decreases slowly as the degree increases. After the application of the optimal filter, some coefficients near the maximum degree 120 are still not fully suppressed, so that the spectrum of the filtered solutions shows a jump at degree 120 . So far, we solved this problem by an additional application of an empirically designed fan filter. Naturally, a better solution would be to design the filter in a less subjective way (for example, on the basis of a certain optimality criterion). A more radical (though CPU-consuming) solution would be to use as input unconstrained solutions computed to a high spherical harmonic degree (presumably, 150-200). We believe that setting a sufficiently high maximum degree will fully solve the problem of ringing artifacts.

Acknowledgments We thank three anonymous reviewers and Prof. Nico Sneeuw, the handling editor, for the help in improving the manuscript. The work was sponsored by the Stichting Nationale Computerfaciliteiten (National Computing Facilities Foundation, NCF) for the use of supercomputer facilities, with financial support from the Nederlandse organisatie voor Wetenschappelijk Onderzoek (Netherlands Organization for Scientific Research, NWO).

Open Access This article is distributed under the terms of the Creative Commons Attribution License which permits any use, distribution, and reproduction in any medium, provided the original author(s) and the source are credited.

\section{Appendix A: Elimination of discontinuities between 2-year analytical approximations of mass variations}

In this section we provide details on the least-squares adjustment performed in order to eliminate discontinuities between analytical approximations of mass variations over 2-year time intervals. Let us define

$$
\mathbf{B}_{k}\left(\tau^{(k)}\right)=\left[\begin{array}{c}
1 \\
\tau^{(k)} \\
\cos \left(2 \pi \tau^{(k)}\right) \\
\sin \left(2 \pi \tau^{(k)}\right) \\
\cos \left(4 \pi \tau^{(k)}\right) \\
\sin \left(4 \pi \tau^{(k)}\right)
\end{array}\right] \otimes \mathbf{I}_{\mathbf{M}} \quad(k=1,2,3) .
$$

Then, we can write Eq. (13) as

$\mathbf{B}^{\mathrm{T}} \mathbf{w}=\mathbf{0}$,

where

$\mathbf{B}=\left[\begin{array}{cc}\mathbf{B}_{1}(1) & \mathbf{0} \\ -\mathbf{B}_{2}(-1) & \mathbf{B}_{2}(1) \\ \mathbf{0} & -\mathbf{B}_{3}(-1)\end{array}\right]$

and $\mathbf{w}$ is the adjusted counter-part of the vector $\mathbf{v}$ defined according to:

$\mathbf{v}^{\mathrm{T}}=\left[\left(\mathbf{z}^{(1)}\right)^{\mathrm{T}},\left(\mathbf{z}^{(2)}\right)^{\mathrm{T}},\left(\mathbf{z}^{(3)}\right)^{\mathrm{T}}\right]$.

We formulate the adjustment problem as a minimization of the objective function

$$
\Phi(\mathbf{w})=(\mathbf{w}-\mathbf{v})^{\mathrm{T}} \mathbf{S}^{-1}(\mathbf{v})(\mathbf{w}-\mathbf{v})
$$


under the condition given by Eq. (22); matrix $\mathbf{S}(\mathbf{v})$ being defined as the covariance matrix of noise in the vector $\mathbf{v}$ :

$\mathbf{S}(\mathbf{v})=\left[\begin{array}{ccc}\mathbf{S}\left(\mathbf{z}^{(1)}\right) & \mathbf{0} & \mathbf{0} \\ \mathbf{0} & \mathbf{S}\left(\mathbf{z}^{(2)}\right) & \mathbf{0} \\ \mathbf{0} & \mathbf{0} & \mathbf{S}\left(\mathbf{z}^{(3)}\right)\end{array}\right]$.

It is easy to show that the adjusted vector $\mathbf{w}$ is given by the following expression:

$\mathbf{w}=\mathbf{v}-\mathbf{S}(\mathbf{v}) \mathbf{B}\left(\mathbf{B}^{\mathrm{T}} \mathbf{S}(\mathbf{v}) \mathbf{B}\right)^{-1} \mathbf{B}^{\mathrm{T}} \mathbf{v}$.

The covariance matrix of noise in $\mathbf{w}$ is obtained as

$\mathbf{S}(\mathbf{w})=\mathbf{S}(\mathbf{v})-\mathbf{S}(\mathbf{v}) \mathbf{B}\left(\mathbf{B}^{\mathrm{T}} \mathbf{S}(\mathbf{v}) \mathbf{B}\right)^{-1} \mathbf{B}^{\mathrm{T}} \mathbf{S}(\mathbf{v})$.

\section{References}

Abdalati W, Krabill W, Frederick E, Manizade S, Martin C, Sonntag J, Swift R, Thomas R, Wright W, Yungel J (2001) Outlet glacier and margin elevation changes: near-coastal thinning of the Greenland ice sheet. J Geophys Res 106(D24):33729-33741

Baur O, Kuhn M, Featherstone WE (2009) GRACE-derived ice-mass variations over Greenland by accounting for leakage effects. J Geophys Res 114:B06407. doi:10.1029/2008JB006239

Baur O, Sneeuw N (2011) Assessing Greenland ice mass loss by means of point-mass modeling: a viable methodology. J Geod 85: 607-615. doi:10.1007/s00190-011-0463-1

Bettadpur SV (2007) UTCSR level-2 processing standards document for Level-2 product release 0004. Center for Space Research, University of Texas at Austin

Chen JL, Wilson CR, Seo K-W (2009) $S_{2}$ tide aliasing in GRACE time variability gravity solutions. J Geod 83:679-687. doi:10.1007/ s00190-008-0282-1

Förste C, Schmidt R, Stubenvoll R, Flechtner F, Meyer U, König R, Neumayer H, Biancale R, Lemoine J-M, Bruinsma J, Loyer S, Barthelmes F, Esselborn S (2008) The GeoForschungsZentrum Potsdam/Groupe de Recherche de Gèodésie Spatiale satellite-only and combined gravity field models: EIGEN-GL04S1 and EIGENGL04C. J Geod 82:331-346. doi:10.1007/s00190-007-0183-8

Gardner AS, Moholdt G, Wouters B, Wolken GJ, Burgess DO, Sharp MJ, Cogley JG, Braun C, Labine C (2011) Sharply increased mass loss from glaciers and ice caps in the Canadian Arctic Archipelago. Nature 473:357-360. doi:10.1038/nature10089

Ilk K-H, Feuchtinger M, Mayer-Gürr T (2005) Gravity field recovery and validation by analysis of short arcs of a satellite-to-satellite tracking experiment as CHAMP and GRACE. In: Sansò F (ed) A window on the future of geodesy. IUGG General Assembly 2003, June 30-July 11 2003, Sapporo. International Association of Geodesy Symposia. Springer, Berlin, vol 128, pp 189-194

IPCC (2007) Climate Change 2007: The Physical Science Basis. Contribution of Working Group I to the Fourth Assessment Report of the Intergovernmental Panel on Climate Change. In: Solomon S, Qin D, Manning M, Chen Z, Marquis M, Averyt KB, Tignor M, Miller HL (eds) Cambridge University Press, Cambridge

Khan SA, Wahr J, Bevis M, Velicogna I, Kendrick E (2010) Spread of ice mass loss into northwest Greenland observed by GRACE and GPS. Geophys Res Lett 37:L06501. doi:10.1029/2010GL042460

Klees R, Revtova EA, Gunter BC, Ditmar P, Oudman E, Winsemius HC, Savenije HHG (2008) The design of an optimal filter for monthly GRACE gravity models. Geophys J Int 175:417-432. doi:10.1111/ j.1365-246X.2008.03922.x

Krabill W, Abdalati W, Frederick E, Manizade S, Martin C, Sonntag J, Swift R, Thomas R, Wright W, Yungel J (2000) Greenland ice sheet: high-elevation balance and peripheral thinning. Science 289:428-430. doi:10.1126/science.289.5478.428

Krabill W, Hanna E, Huybrechts P, Abdalati W, Cappelen J, Csatho B, Frederick E, Manizade S, Martin C, Sonntag J, Swift R, Thomas R (2004) Greenland ice sheet: increased coastal thinning. Geophys Res Lett 31:L24402. doi:10.1029/2004GL021533

Lemoine JM, Bruinsma S, Loyer S, Biancale R, Marty JC, Perosanz F, Balmino G (2007) Temporal gravity field models inferred from GRACE data. Adv Space Res 39:1620-1629

Liu X, (2008) Global gravity field recovery from satellite-to-satellite tracking data with the acceleration approach ( $\mathrm{PhD}$ thesis). Nederlands Geodetic Comission, Publications on Geodesy, vol 68, Delft

Liu X, Ditmar P, Siemes C, Slobbe DC, Revtova E, Klees R, Riva R, Zhao Q (2010) DEOS mass transport model (DMT-1) based on GRACE satellite data: methodology and validation. Geophys J Int 181:769-788

Luthcke SB, Zwally HJ, Abdalati W, Rowlands DD, Ray RD, Nerem RS, Lemoine FG, McCarthy JJ, Chinn DS (2006) Recent Greenland ice mass loss by drainage system from satellite gravity observations. Science 314: 1286-1289. doi:10.1126/science.1130776

Luthcke SB, Rowlands DD, Lemoine FG, Klosko SM, Chinn D, McCarthy JJ (2006) Monthly spherical harmonic gravity field solutions determined from GRACE inter-satellite range-rate data alone. Geophys Res Lett 33:L02402. doi:10.1029/2005GL024846

Lyard F, Lefevre F, Letellier T, Francis O (2006) Modelling the global ocean tides: insights from FES2004. Ocean Dyn 56:394-415

Peltier WR (2004) Global glacial isostasy and the surface of the ice-age earth: the ICE-5G (VM2) model and GRACE. Annu Rev Earth Planet Sci 32: 111-149. doi:10.1146/annurev.earth.32.082503. 144359

Rignot E, Kanagaratnam P (2006) Changes in the velocity structure of the Greenland ice sheet. Science 311: 986-990. doi:10.1126/ science. 1121381

Rignot E, Velicogna I, van den Broeke MR, Monaghan A, Lenaerts JTM (2011) Acceleration of the contribution of the Greenland and Antarctic ice sheets to sea level rise. Geophys Res Lett 38:L05503. doi:10.1029/2011GL046583

Schmidt R (2007) Static field geopotential coefficients estimated from satellite data only. Digital media, GFZ Potsdam GRACE science data system. Oberpfaffenhofen, Germany

Schrama EJO, Wouters B (2011) Revisiting Greenland ice sheet mass loss observed by GRACE. J Geophys Res 116:B02407. doi:10. 1029/2009JB006847

Slobbe DC, Lindenbergh R, Ditmar P (2008) Estimation of volume change rates of Greenland's ice sheet from ICESat data. Remote Sensing Environ 112:4204-4213

Slobbe DC, Ditmar P, Lindenbergh RC (2009) Estimating the rates of mass change, ice volume change and snow volume change in Greenland from ICESat and GRACE data. Geophys J Int 176: 95-106. doi:10.1111//j.1365-246X.2008.03978.x

Sørensen LS, Simonsen SB, Nielsen K, Lucas-Picher P, Spada G, Adalgeirsdottir G, Forsberg R, Hvidberg CS (2011) Mass balance of the Greenland ice sheet (2003-2008) from ICESat data-the impact of interpolation, sampling, and firn density. Cryosphere 5:173-186

Stearns LA, Hamilton GS (2007) Rapid volume loss from two East Greenland outlet glaciers quantified using repeat stereo satellite imagery. Geophys Res Lett 34:L05503. doi:10.1029/ 2006GL028982

Tapley B, Bettadpur S, Watkins M, Reigber C (2004) The gravity recovery and climate experiment: mission overview and early results. Geophys Res Lett 31:L09607. doi:10.1029/2004GL019920

Van den Broeke M, Bamber J, Ettema J, Rignot E, Schrama E, van de Berg WJ, van Meijgaard E, Velicogna I, Wouters B (2009) Partitioning recent Greenland mass loss. Science 326:984-986. doi:10. 1126/science. 1178176 
Velicogna I, Wahr J (2006) Acceleration of Greenland ice mass loss in spring 2004. Nature 443: 329-331. doi:10.1038/nature05168

Velicogna I (2009) Increasing rates of ice mass loss from the Greenland and Antarctic ice sheets revealed by GRACE. Geophys Res Lett 36:L19503. doi:10.1029/2009GL040222

Wahr J, Molenaar M, Bryan F (1998) Time variability of the Earth's gravity field: hydrological and oceanic effects and their possible detection using GRACE. J Geophys Res 103(B12):30205-30229

Wahr J, Swenson S, Velicogna I (2006) Accuracy of GRACE mass estimates. Geophys Res Lett 33:L06401. doi:10.1029/2005GL025305

Wouters B, Chambers D, Schrama EJO (2008) GRACE observes smallscale mass loss in Greenland. Geophys Res Lett 35:L20501. doi:10.1029/2008GL034816

Zhang Z-Z, Chao BF, Lu Y, Hsu H-T (2009) An effective filtering for GRACE time-variable gravity: fan filter. Geophys Res Lett 36:L17311. doi:10.1029/2009GL039459
Zwally HJ, Schutz B, Abdalati W, Abshire J, Bently C, Brenner A, Bufton J, Dezio J, Hancock D, Harding D, Herring T, Minster B, Quinn K, Palmi S, Spinhirne J, Thomas R (2002) ICESat's laser measurements of polar ice, atmosphere, ocean, and land. J Geodyn 34:405-445

Zwally HJ, Giovinetto MB, Li J, Cornejo HG, Beckley MA, Brenner AC, Saba JL, Yi D (2005) Mass changes of the Greenland and Antarctic ice sheets and shelves and contributions to sea-level rise: 1992-2002. J Glaciol 51(175):509-527

Zwally HJ, Li J, Brenner A, Beckley M, Cornejo HG, Dimarzio J, Giovinetto MB, Neumann TA, Robbins J, Saba JL, Yi D, Wang W (2011) Greenland ice sheet mass balance: distribution of increased mass loss with climate warming; 2003-2007 versus 1992-2002. J Glaciol 57:88-102 